Goldschmidt 2021 Abstract

https://doi.org/10.7185/gold2021.5762

\section{Lactation and gestation influence the body calcium isotope composition: insights from wild and domestic mammals}

\author{
AUGUSTE HASSLER ${ }^{1}$, JEREMY MARTIN ${ }^{2}$, STÉPHANE \\ FERCHAUD $^{3}$, DORYAN GRIVAULT ${ }^{3}$, GILDAS \\ MERCERON $^{4}$, MATHIEU GAREL ${ }^{5}$, THÉO TACAIL $^{6}$, \\ SAMUEL LE GOFF ${ }^{7}$, EMMANUELLE ALBALAT $^{8}$, JEAN- \\ ALEXIS HERNANDEZ ${ }^{9}$ AND VINCENT BALTER ${ }^{7}$
}

${ }^{1} \mathrm{CNRS}$, LGL-TPE

${ }^{2}$ Univ Lyon, ENSL, Univ Lyon 1, CNRS, LGL-TPE

${ }^{3}$ Institut national de recherche pour l'agriculture, l'alimentation et l'environnement (INRAE)

${ }^{4}$ PALEVOPRIM, UMR 7262 CNRS \& Université de Poitiers

${ }^{5}$ Office Français de la Biodiversité (OFB; ex-ONCFS)

${ }^{6}$ Johannes Gutenberg-Universität Mainz, Institut für Geowissenschaften

${ }^{7}$ ENS de Lyon, Univ Lyon 1, CNRS UMR 5276, LGL-TPE

${ }^{8}$ Laboratoire de géologie de Lyon UMR 5276, ENS et Université Lyon 1

${ }^{9}$ University of Oslo

Presenting Author: auguste.hassler@hotmail.fr

Milk production and excretion may drive sex specific differences in body calcium (Ca) isotope composition, as evidenced by sheep bones collected within a single herd [1]. Such differences between sexes are however not observed in human populations [2], raising questions about $\mathrm{Ca}$ isotope fractionation mechanisms in mammals. We investigated this issue by studying a free-ranging red deer population and three female pigs raised under controlled conditions. We coupled this experimental approach with box-modeling of a female pig-like animal experiencing different scenarios of $\mathrm{Ca}$ fluxes and isotopic fractionations. The wild red deer population exhibits a similar male/female isotopic difference $\left(\Delta^{44 / 42} \mathrm{Ca}_{\text {lactating females-males }}=+0.17\right.$ $\pm 0.10 \%)$ compared to domestic sheep $\left(\Delta^{44 / 42} \mathrm{Ca}_{\text {females-males }}=\right.$ $+0.14 \pm 0.08 \%$ [1]), demonstrating that sheep are not an isolated case. The experiment with domestic pigs and associated modeling confirm that bone ${ }^{44} \mathrm{Ca}$ relative enrichment occurs during nursing as a consequence of lactation. Our data also suggest that consecutive gestations and associated high $\mathrm{Ca}$ intakes (e.g. in animal husbandry contexts), can reduce the isotopic offset between animal tissues and diet (e.g. $\Delta^{44 / 42} \mathrm{Ca}_{\text {bone- }}$ diet), an essential finding for accurately interpreting $\mathrm{Ca}$ isotopes as a diet proxy in mammal past communities. Finally, in line with other publications (see Tacail et al. 2020 and reference therein [3]), our experimental and modeling results also support that bone mineralization is associated with a more restricted $\mathrm{Ca}$ isotopic fractionation than previously envisioned. A result which has notable implications for the use of $\mathrm{Ca}$ isotopes as a human bone balance proxy and osteoporosis diagnostic tool.

\section{References:}

[1] Reynard LM, Henderson GM, Hedges REM (2010), Geochimica et Cosmochimica Acta 74(13), 3735-3750, doi:10.1016/j.gca.2010.04.002

[2] Reynard LM, Pearson JA, Henderson GM, Hedges REM (2013), Archaeometry 55(5), 946-957, doi:10.1111/j.14754754.2012.00715.x

[3] Tacail T, Le Houedec S, Skulan JL (2020), Chemical Geology 537, 119471, doi:10.1016/j.chemgeo.2020.119471 